\title{
QUANTIFICAÇÃO DE MACRONUTRIENTES NO SOLO E EM FOLHAS DE CANA-DE- AÇÚCAR EM FUNÇÃO DE DOSES DE RESÍDUO DA MINERAÇÃO DE BAUXITA ${ }^{1}$
}

\author{
FABIO O. DE NOBILE ${ }^{2}$, JOÃO A. GALBIATTI ${ }^{3}$, REGINALDO MURAISHI ${ }^{2}$, \\ ADRIANO G. RIBEIRO ${ }^{2}$, ONÃ DA S. FREDDI ${ }^{4}$
}

\begin{abstract}
RESUMO: O experimento foi realizado em ambiente protegido, com o objetivo de avaliar o efeito do resíduo da mineração de bauxita nos teores de macronutrientes, no solo e em plantas de cana-de-açúcar. Foram utilizados vasos de $10 \mathrm{~L}$ que receberam as seguintes doses de resíduo de bauxita: 0; 28;56; 84; 112 e $140 \mathrm{t} \mathrm{ha}^{-1}$, utilizando-se do clone de cana-de-açúcar SP92 4221. A incorporação do resíduo de bauxita no solo proporcionou aumento nos teores dos macronutrientes do solo, sendo que apenas para o enxofre doses acima de $83 \mathrm{t} \mathrm{ha}^{-1}$ proporcionaram reduções desse nutriente. Já para os teores de macronutrientes determinados na folha, doses acima de 70,5; 125; $101 \mathrm{e} 56 \mathrm{t} \mathrm{ha}^{-1}$ diminuíram os teores de nitrogênio, fósforo, potássio e enxofre, respectivamente. Entretanto, para o cálcio e o magnésio, a utilização do resíduo proporcionou a diminuição dos seus teores foliares. A dose do resíduo de bauxita que teve a maior produção de massa seca foi de $64 \mathrm{t} \mathrm{ha}^{-1}$.
\end{abstract}

PALAVRAS-CHAVE: Sacharum oficinarum, condicionador de solo, resíduo.

\section{NUTRIENT DIAGNOSIS OF SUGARCANE IN FUNCTION OF RESIDUE RATES OF THE BAUXITE MINING}

\begin{abstract}
The experiment was carried out in green house with the objective of evaluating the effect of the bauxite mining residue in the rates of macronutrients in sugarcane and soil. Containers of $10 \mathrm{~L}$ were used. They received the following rates of bauxite residue: $0 ; 28 ; 56 ; 84 ; 112$ and $140 \mathrm{t} \mathrm{ha}^{-1}$. The used culture was the sugarcane (SP92 4221). The incorporation of the bauxite residue in the soil provided an increase in the levels of the soil macronutrients, and only for sulphur levels above $83 \mathrm{t} \mathrm{ha}^{-1}$, it was possible to provide reductions of this nutrient. For rates of determined macronutrients in the leaf, levels above 70,$5 ; 125 ; 101 ; 56 \mathrm{t} \mathrm{ha}^{-1}$ diminished the rates of nitrogen, phosphorum, potassium and sulphur, respectively. However, for calcium and magnesium the use of the residue provided the reduction of leaf rates. The level of the bauxite residue which had the largest production of dry mass was $64 \mathrm{t} \mathrm{ha}^{-1}$.
\end{abstract}

KEYWORDS: Sacharum oficinarum, soil conditioners, residue.

\section{INTRODUÇÃO}

O resíduo alcalino do refino da bauxita, também denominado "lama vermelha" (red mud), é gerado do processo de extração de alumina da bauxita. A alumina hidratada ocorre na bauxita como gibsita, também chamada hidrargilita $\left(\mathrm{Al}_{2} \mathrm{O}_{3} \cdot 3 \mathrm{H}_{2} \mathrm{O}\right)$ e como boemita e diásporo, nas formas de mono-hidrato $\left(\mathrm{Al}_{2} \mathrm{O}_{3} \cdot \mathrm{H}_{2} \mathrm{O}\right)$. As principais impurezas encontradas na bauxita são os compostos de sílica, ferro e titânio.

O comportamento desses compostos no beneficiamento da bauxita é de fundamental importância na obtenção de um produto final (alumina) de qualidade desejada, assim como na composição do resíduo de bauxita (WONG, 1990). A composição química é característica de cada

\footnotetext{
${ }^{1}$ Extraído da Dissertação de Mestrado do primeiro autor.

${ }^{2}$ Aluno do Programa de Pós-Graduação em Produção Vegetal, Faculdade de Ciências Agrárias e Veterinárias, FCAV/UNESP, Jaboticabal - SP, fonobile@ fcav.unesp.br, Bolsista CNPq.

${ }^{3}$ Eng $^{\mathrm{o}}$ Agrônomo, Prof. Titular, Departamento de Engenharia Rural, Faculdade de Ciências Agrárias e Veterinárias, FCAV/UNESP, Jaboticabal - SP, galbi@fcav.unesp.br

${ }^{4}$ Aluno do Programa de Pós-Graduação em Produção Vegetal, Faculdade de Ciências Agrárias e Veterinárias, FCAV/UNESP, ona_freddi@yahoo.com.br, Bolsista FAPESP.
}

Recebido pelo Conselho Editorial em: 25-10-2007

Aprovado pelo Conselho Editorial em: 12-12-2009

Eng. Agríc., Jaboticabal, v.30, n.1, p.168-178, jan./fev. 2010 
resíduo de bauxita, dependendo do minério do qual é derivado, e também do processado e das condições industriais a que a bauxita foi submetida para a extração da alumina. Pode também ser afetada pela granulometria do minério de bauxita e da água utilizada no processo industrial (WONG, 1990).

Estudos têm demonstrado que o resíduo de bauxita tem grande potencial de uso como material na construção civil, fabricação de agregados para utilização em concretos pré-moldados na construção civil (SOUZA, 1989), na construção de estradas, melhorando a adesão asfáltica (HARTLEY \& THORPE, 1980) e em algumas formas de uso em sistemas agrícolas, por exemplo, como condicionador de solo (WARD, 1986).

FERREIRA (2001), estudando resíduo do processamento de bauxita na elevação do pH de dois solos ácidos e absorção de cálcio pelo trevo, não identificou nenhum efeito tóxico nas plantas cultivadas; no entanto, o resíduo promoveu menor absorção de potássio, o que deve estar associado a sua alta concentração de sódio, competindo com o potássio.

Para avaliar a adsorção de fósforo do resíduo de bauxita, FORTIN \& KARAM (2001) demonstraram que a adsorção de fósforo tem relação direta com o teor de fósforo adicionado ao resíduo. Os mesmos ainda citaram que o aumento da absorção do nutriente tem grande relação com o aumento do tempo de reação de absorção no solo.

A cana-de-açúcar é uma cultura adequada para o uso de resíduos, uma vez que não é de consumo direto (com exceção da alimentação animal), sendo plantada em grandes extensões e dotada de grande tecnologia (NOBILE, 2003). Portanto, o trabalho teve como objetivo avaliar o efeito da incorporação no solo do resíduo de bauxita nos teores de macronutrientes do solo, das folhas e a produção de massa seca da cultura da cana-de-açúcar.

\section{MATERIAL E MÉTODOS}

O experimento foi desenvolvido em ambiente protegido, do tipo arco conjugado, coberto por filme plástico de polietileno específico para esse fim e tela antiafídica em toda sua área externa, localizado no setor de Plasticultura, do Departamento de Engenharia Rural, da UNESP - Faculdade de Ciências Agrárias e Veterinárias, Câmpus de Jaboticabal - SP, cujas coordenadas geográficas são $21^{\circ} 15^{\prime} 15^{\prime}$ ' latitude sul, 48 $18^{\circ}$ '09' longitude oeste, e altitude em torno de $595 \mathrm{~m}$.

Utilizaram-se amostras de solo oriundo de um Latossolo Vermelho distrófico de mata mesófila semidecídua residual, textura média, retiradas na camada de 0-20 cm, cuja densidade foi de $1,3 \mathrm{~kg} \mathrm{dm}^{-3}$.

As análises químicas e granulométricas foram realizadas no Departamento de Solos e Adubos, da Faculdade de Ciências Agrárias e Veterinárias - Câmpus de Jaboticabal (Tabela 1), conforme metodologia descrita por RAIJ et al. (2001).

TABELA 1. Caracterização química e granulométrica do solo. Chemical and granulometric soil characterization.

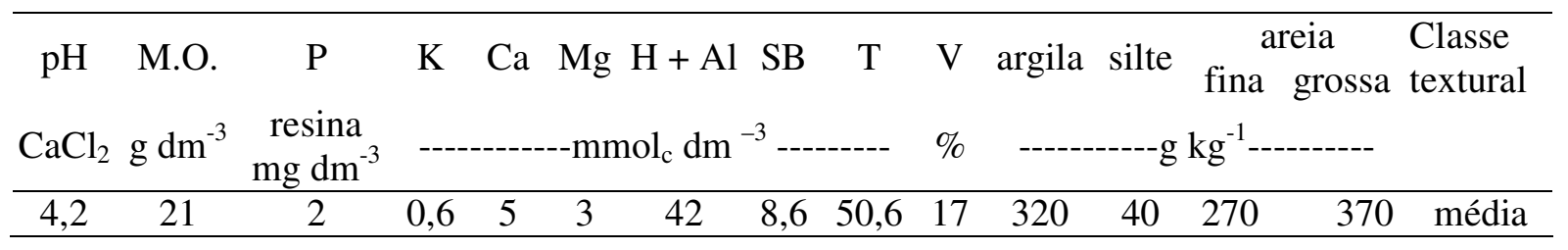

O resíduo de bauxita foi seco, moído e peneirado (peneira ABNT 20). O material, depois de peneirado e homogeneizado, foi submetido à análise química, conforme metodologia descrita por LANARV (1988), sendo realizada no laboratório de química da ALCOA Alumínio S.A. - MG (Tabela 2). 
TABELA 2. Caracterização química do resíduo de bauxita. Chemical characterization of bauxite residue.

\begin{tabular}{|c|c|c|c|c|c|c|c|c|c|c|c|}
\hline $\mathrm{N}$ & K & $\mathrm{Ca}$ & $\mathrm{Mg}$ & $\mathrm{S}$ & $\mathrm{P}$ & $\mathrm{Zn}$ & $\mathrm{Mn}$ & $\mathrm{Fe}$ & $\mathrm{Cu}$ & $\mathrm{Na}$ & $\mathrm{pH}$ \\
\hline & & g & & & & & & $\mathrm{mg} \mathrm{kg}^{-1}$ & & ----- & $\mathrm{CaCl}_{2}$ \\
\hline 4,9 & 12,6 & 26,9 & 0,5 & 1,5 & 0,001 & 133 & 110 & 138.000 & 7 & 61.000 & 11 \\
\hline
\end{tabular}

Em vasos de polietileno, com capacidade para $10 \mathrm{~L}$, foram testadas seis doses de resíduo de bauxita: testemunha $(0) ; 2 ; 4 ; 6 ; 8$ e $10 \%$ do volume do vaso, correspondendo a: testemunha (0);28;56; 84; 112 e $140 \mathrm{t} \mathrm{ha}^{-1}$ resíduo do processamento de bauxita, sendo que o cálculo para estimar a quantidade de resíduo em $\mathrm{t} \mathrm{ha}^{-1}$ levou em consideração a camada de $0-20 \mathrm{~cm}$ do solo. A escolha das doses foi feita com base em ensaio preliminar com volumes maiores de resíduo de bauxita $(0 ; 10 ; 20 ; 30 ; 40 ; 50 ; 60 ; 70 ; 80$ e $100 \%$ em vasos de $10 \mathrm{~L})$.

Para a instalação do experimento, efetuou-se, primeiramente, a peneiração do solo para retirar todos os agregados maiores e resíduos grosseiros de material orgânico. Feito isso, misturaram-se o solo e o resíduo da extração de bauxita, com o auxílio de um saco de plástico, em função dos tratamentos.

Depois do preenchimento dos vasos, procedeu-se ao plantio da cana-de-açúcar (SP92 4221), em 2 de outubro de 2003, em profundidade de $15 \mathrm{~cm}$. Foram utilizadas mudas provenientes de cultura de tecidos apresentando três plantas de cana-de-açúcar por muda, com $10 \mathrm{~cm}$ de altura cada, sendo estabelecido uma muda de cana-de-açúcar para cada vaso do experimento. A colheita do experimento foi realizada no dia 27 de janeiro de 2004, depois de 118 dias do desenvolvimento da planta. As mudas foram obtidas junto à Usina Santa Adélia, localizada no município de Guariba-SP.

Foram feitas irrigações diárias calculadas com base na recomendação de água pelo método do tanque Classe A e seguindo metodologia de MONTERO et al. (1985), em que a evapotranspiração das culturas sob ambiente protegido é normalmente 60 a $80 \%$ da evapotranspiração do ambiente exterior. Especificamente para este estudo, usou-se a média $70 \%$, devido à grande exigência da cultura em água. O Kc da cultura da cana-de-açúcar utilizado para o cálculo da quantidade de água a ser aplicada por vaso foi de 0,7 (DOORENBOS \& KASSAM, 1994), correspondente à fase estudada neste trabalho.

No final do experimento, foram coletadas a folha diagnóstica +3 das plantas e colocadas dentro de sacos plásticos, identificadas e levadas ao laboratório do Departamento de Engenharia Rural da Faculdade de Ciências Agrárias e Veterinárias, Câmpus de Jaboticabal. No laboratório, as folhas foram lavadas com água de torneira e enxaguadas com água destilada. Folhas secas, murchas ou deterioradas foram excluídas, porque os elementos químicos podem ser dissolvidos na água de lavagem, causando perdas irreversíveis. Após as lavagens, as folhas foram colocadas em saco de papel, secas em estufa de circulação forçada de ar a $60{ }^{\circ} \mathrm{C}$ até peso constante, em seguida foram trituradas em moinho do tipo Wiley, passadas em peneiras de malha 1,0 $\mathrm{mm}$ (20 mesh) e finalmente armazenadas para subsequente análise química.

No final da secagem e antes de ser triturado, o material, ou seja, a planta toda foi pesada para a determinação da quantidade de massa seca por vaso $\left(\mathrm{g}\right.$ vaso $\left.^{-1}\right)$.

Todas as metodologias descritas para a análise de nutrientes (N, P, K, Ca, Mg e S) na planta seguem os métodos sugeridos por MALAVOLTA et al. (1997).

Para a coleta da amostras simples do solo, foram escolhidos seis pontos ao redor da base da plantas, numa profundidade de $20 \mathrm{~cm}$, sendo as seis amostras simples misturadas para a obtenção de uma amostra composta. As análises químicas seguiram metodologia descrita por RAIJ et al. (2001).

Os resultados foram submetidos à análise de variância e de regressão entre as doses de resíduo de bauxita, e os macronutrientes do solo, da planta e da massa seca da cana-de-açúcar, de acordo com os procedimentos do STATISTICAL ANALYSIS SYSTEM (SAS Institute, 1999). 


\section{RESULTADOS E DISCUSSÃO}

\section{Nutrientes no solo}

A aplicação de doses do resíduo de bauxita $\left(0\right.$ a $\left.140 \mathrm{t} \mathrm{ha}^{-1}\right)$ elevou o valor de $\mathrm{pH}$ do solo de 4,4 para 6,7, descrevendo uma função linear (Figura 1a). A causa da elevação do pH está na alcalinidade do resíduo de bauxita (Tabela 2), explicado pela presença de carbonato de cálcio adicionado ao resíduo para a eliminação do fósforo, e hidroxilas $\left(\mathrm{OH}^{-}\right)$presentes na soda cáustica, que também está adicionada ao resíduo para a extração do alumínio. Com o resíduo rico em hidroxilas e carbonatos, esses reagirão com o $\mathrm{H}^{+}$da solução do solo, elevando o $\mathrm{pH}$. A tendência é que $\mathrm{o} \mathrm{pH}$ aumente a cada aumento na dose de resíduo de bauxita, $\mathrm{o} \mathrm{pH}$ tenderia à neutralidade.

FERREIRA (2001), utilizando resíduo de bauxita em solo, verificou mudança semelhante no comportamento do $\mathrm{pH}$, também devido à presença de hidroxilas que atuam na neutralização de íons $\mathrm{H}^{+}$. De acordo com o RAIJ et al. (1997), a acidez do solo com a aplicação do resíduo de bauxita passou de um limite alto ( $\mathrm{pH}$ de 4,4 - 5,0) para um limite muito baixo (dose de $140 \mathrm{t} \mathrm{ha}^{-1}$ ).

Os teores de fósforo no resíduo de bauxita são baixos (Tabela 2), semelhante à condição verificada na maioria dos solos brasileiros (RAIJ, 1991). O baixo teor de fósforo do resíduo é função da formação de compostos insolúveis com o cálcio. A quantidade de fósforo presente no resíduo é muito baixo, em torno de $1 \mathrm{a} 2 \mathrm{mg} \mathrm{dm}^{-3}$. Entretanto, observou-se aumento linear do teor de fósforo do solo com o incremento do resíduo no solo. Segundo FERREIRA (2001), a possibilidade para o aumento de fósforo no solo está na elevação do $\mathrm{pH}$ causado pela adição do resíduo; com o aumento do $\mathrm{pH}$, o fósforo adsorvido nos coloides do solo passariam para a solução tornando-se disponíveis para as plantas, sendo a maior disponibilidade $\mathrm{em} \mathrm{pH}$ ao redor de seis.

ROBERTSON et al. (1997), avaliando os teores de fósforo em solos que receberam resíduo de bauxita $\left(60 \mathrm{t} \mathrm{ha}^{-1}\right)$, também constataram aumento do elemento no solo à medida que se aumentava a dose de resíduo de bauxita. Todas as doses testadas aumentaram significativamente os teores no solo, comparados com os valores encontrados para a testemunha. Resultados semelhantes foram encontrados por McPHARLIN et al. (1994) que, aplicando 0; 60; 120 e $240 \mathrm{t} \mathrm{ha}^{-1}$ de resíduo de bauxita para avaliar a lixiviação do fósforo, observaram que o fósforo retido na camada de $0-15 \mathrm{~cm}$ do solo aumentou em $34 \%$.

Os teores de fósforo com a aplicação de resíduo de bauxita estão dentro dos limites considerados baixos (6-12 $\mathrm{mg} \mathrm{dm}^{-3}$ ) por RAIJ et al. (1997), com exceção da aplicação de $140 \mathrm{t} \mathrm{ha}^{-1}$, que ficou na faixa considerada média (13-30 $\left.\mathrm{mg} \mathrm{dm}^{-3}\right)$.

Inicialmente, houve redução do teor de potássio do solo até a dose $49 \mathrm{t} \mathrm{ha}^{-1}$ de resíduo e, a partir desse valor, aumento crescente nos teores de potássio foi observado, concordando com os resultados obtidos por WARD (1986). Os teores de potássio encontrados para a testemunha e as doses de 28; 56; 84 e $112 \mathrm{t} \mathrm{ha}^{-1}$ eram considerados muito baixos $\left(0,0-0,7 \mathrm{mmol}_{\mathrm{c}} \mathrm{dm}^{-3}\right)$; já a aplicação no tratamento $140 \mathrm{t} \mathrm{ha}^{-1}$ de resíduo de bauxita elevou os teores para um limite considerado baixo $\left(0,8-1,5 \mathrm{mmol}_{\mathrm{c}} \mathrm{dm}^{-3}\right)$, de acordo com RAIJ et al. (1997).

Os altos valores de cálcio encontrados no resíduo são devido à adição de calcário $\left(\mathrm{CaCO}_{3}\right)$ no processo Bayer de extração da bauxita, interferindo em sua composição química. Logo, a adição do resíduo no solo proporcionou incremento linear no teor de cálcio (Figura 1d) do solo, e com a aplicação de $28 \mathrm{t} \mathrm{ha}^{-1}$ do resíduo, os teores no solo dobraram em relação à testemunha, passando de 8 para $16 \mathrm{mmol}_{\mathrm{c}} \mathrm{dm}^{-3}$ (Figura 1). SUMMERS et al. (1996) também observaram aumento nos teores de cálcio com a aplicação de $40 \mathrm{t} \mathrm{ha}^{-1}$ do resíduo de bauxita. Todas as doses aplicadas elevaram os níveis de cálcio a um limite considerado alto $\left(>7 \mathrm{mmol}_{\mathrm{c}} \mathrm{dm}^{-3}\right)$, de acordo com RAIJ et al. (1997). 

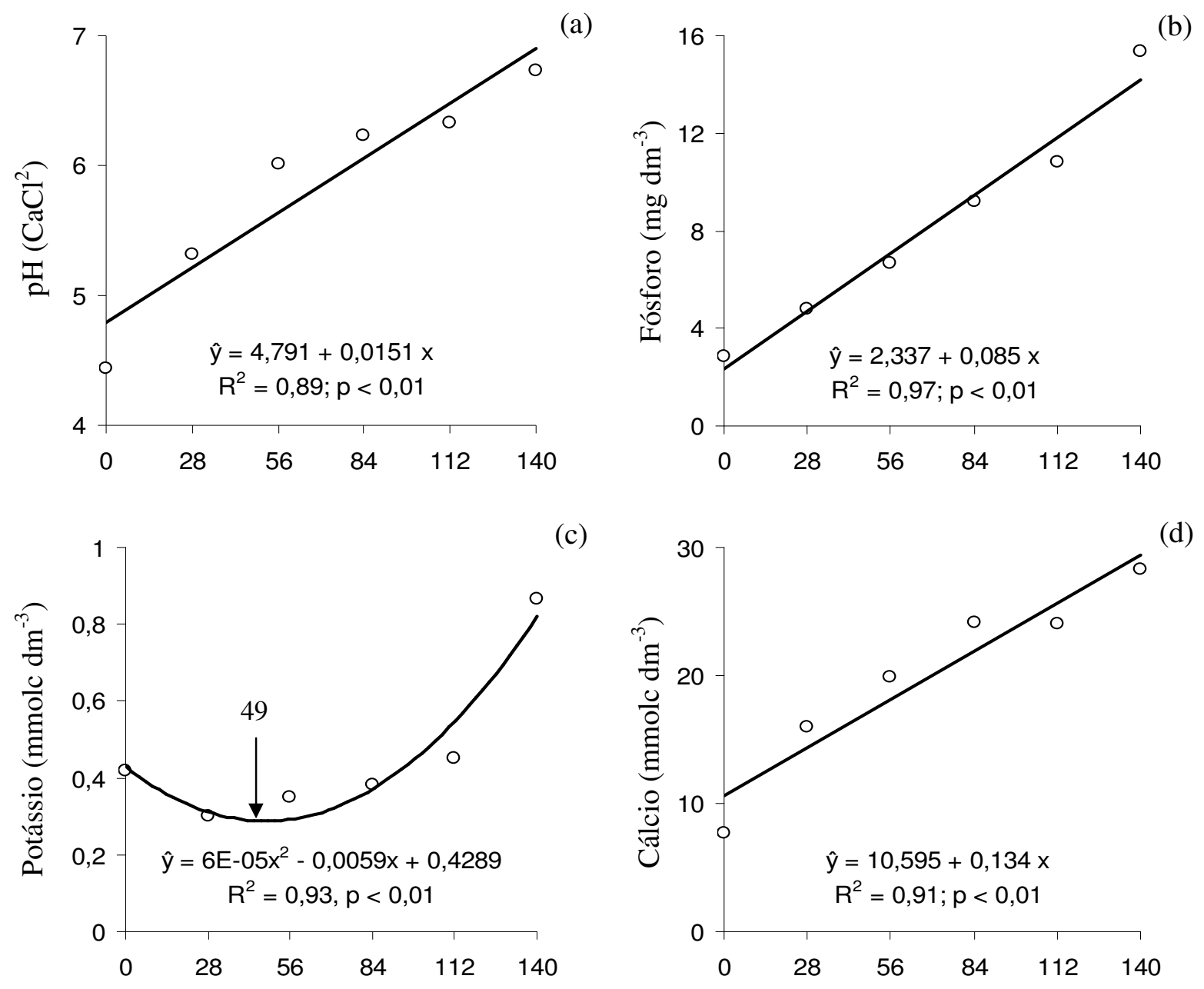

(c)
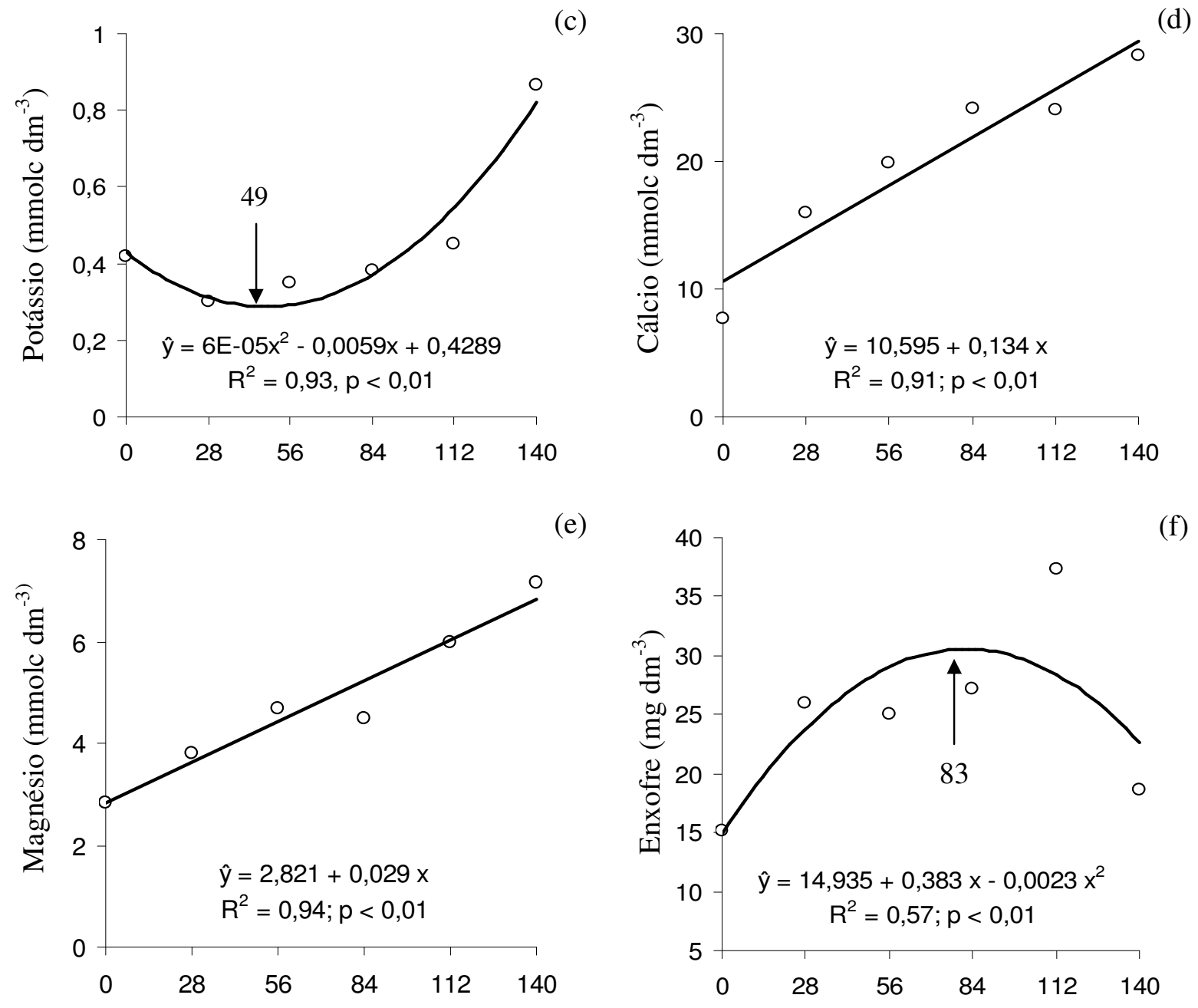

(e)

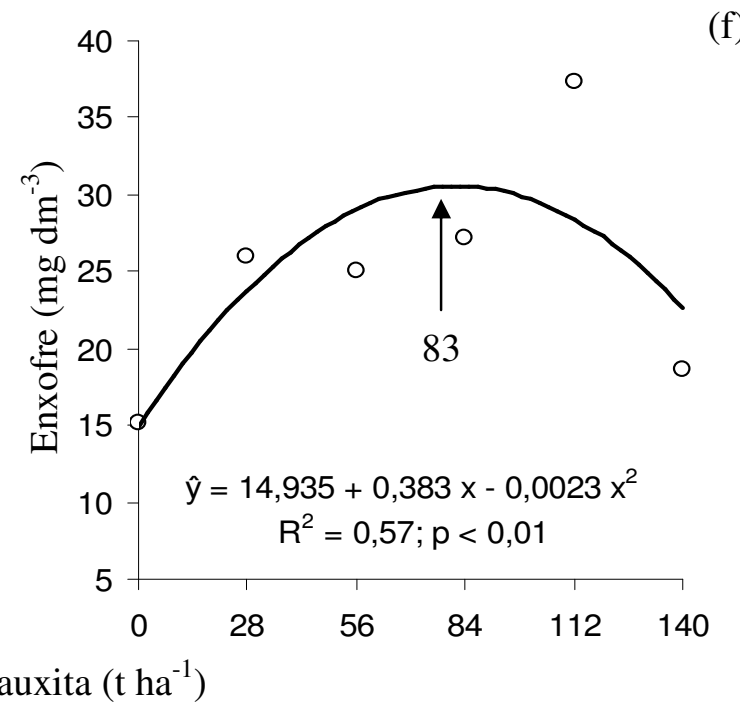

FIGURA 1. Regressões entre as doses de resíduo de bauxita incorporado ao solo e pH $\left(\mathrm{CaCl}_{2}\right)$, teor de fósforo, potássio, cálcio, magnésio e enxofre determinados no solo. Regressions among the doses of bauxite residue incorporated in the soil and $\mathrm{pH}\left(\mathrm{CaCl}_{2}\right)$, rates of phosphorus, potassium, calcium, magnesium and sulfur determined in the soil. 
A quantidade de magnésio presente na testemunha $\left(2,8 \mathrm{mmol}_{\mathrm{c}} \mathrm{dm}^{-3}\right)$ é considerada baixa; contudo, com a aplicação do resíduo de bauxita, esses níveis passaram para limites considerados médios, conforme RAIJ et al. (1997). O aumento das doses do resíduo no solo promoveu aumento linear no teor de magnésio no solo (Figura 1c).

O resíduo de bauxita apresenta baixos teores de magnésio em sua composição, o que não poderia explicar os aumentos do elemento nos diferentes tratamentos, sendo esse aumento devido à elevação de $\mathrm{pH}$ (Figura 1a). Outra possibilidade seria o deslocamento de magnésio devido à grande quantidade de cálcio presente no solo. O cálcio em grande quantidade promoveria o deslocamento de magnésio dos coloides para a solução do solo, aumentando, assim, seus teores disponíveis a cada incremento do resíduo de bauxita. O maior aumento de magnésio (Figura 1e) no solo ocorreu com as doses de 112 e $140 \mathrm{t} \mathrm{ha}^{-1}$, com valores de 6,0 e 7,2 $\mathrm{mmol}_{\mathrm{c}} \mathrm{dm}^{-3}$ de magnésio, respectivamente.

WARD (1986) também verificou a disponibilidade de elementos em solos que foram neutralizados com resíduos de bauxita, observando que houve aumento nos teores de magnésio presentes no solo.

A aplicação do resíduo de bauxita proporcionou aumento do teor de enxofre no solo até a dose de $83 \mathrm{t} \mathrm{ha}^{-1}$, na qual ocorreu a maior concentração de enxofre no solo, sendo o teor encontrado de $37,3 \mathrm{mg} \mathrm{dm}^{-3}$ (Figura 1f). Por outro lado, quando não houve aplicação de resíduo de bauxita, o teor foi de $15,2 \mathrm{mg} \mathrm{dm}^{-3}$ de enxofre, sendo o menor teor de enxofre no solo (Figura 1f). O enxofre é absorvido pelas plantas na forma do ânion $\mathrm{SO}_{4}^{-2}$. Em muitos solos, esse ânion não é retido no solo, sendo facilmente lixiviado. Um fator muito importante na adsorção do enxofre nos coloides do solo é o pH, quanto maior, menor será a adsorção (RAIJ, 1991). Segundo RAIJ (1991), o aumento da disponibilidade do nutriente se dá com o aumento da quantidade do mesmo no solo, portanto a cada incremento de dose de resíduo de bauxita, há aumento significativo nos valores de $\mathrm{pH}$, fazendo com que a quantidade de enxofre presente na solução do solo se eleve.

Percebe-se que, acima de $83 \mathrm{t} \mathrm{ha}^{-1}$ do resíduo, os teores de enxofre no solo diminuíram, o que pode ser atribuído ao aumento do enxofre da solução, fazendo com que o elemento se desloque para a fase sólida, ou seja, algum enxofre passe da solução do solo para a fase sólida, sendo por ele adsorvido (COELHO \& Verlenmgia, 1988). De acordo com RAIJ et al. (1997), em todas as doses do resíduo de bauxita testadas, inclusive o tratamento-testemunha, os teores de enxofre estão no limite considerado alto.

\section{Nutrientes nas folhas}

De acordo com a regressão, doses acima de $70 \mathrm{t} \mathrm{ha}^{-1}$ de resíduo foram prejudiciais para o acúmulo de nitrogênio na planta (Figura 2a). O resíduo de bauxita apresenta nitrogênio em sua composição, o aumento de nitrogênio na planta também pode estar associado a microrganismo, livres existentes no solo. $\mathrm{O}$ aumento do $\mathrm{pH}$ estimula o desenvolvimento microbiano do solo, que degrada a matéria orgânica do solo, disponibilizando nitrogênio às plantas, semelhante ao que ocorre na reforma do canavial (NOBILE, 2005).

Assim, nos solos de vegetação nativa, onde o teor de nitrogênio é mantido a baixo nível, a fixação não simbiótica pode ter importante contribuição na acumulação de nitrogênio no solo. As condições que favorecem a fixação não simbiótica de nitrogênio são: alto conteúdo de cálcio e matéria orgânica rica em carbono (COELHO \& VERLEMGIA, 1988). Todos os teores de nitrogênio na planta, nas diferentes doses, estão de acordo com teores mínimos estabelecidos por RAIJ (1991) $\left(1,30 \mathrm{~g} \mathrm{~kg}^{-1}\right)$. 


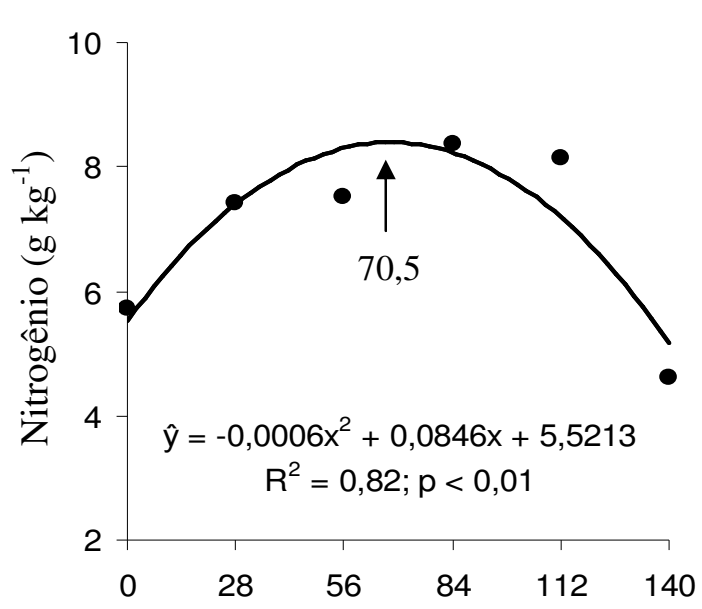

(a)

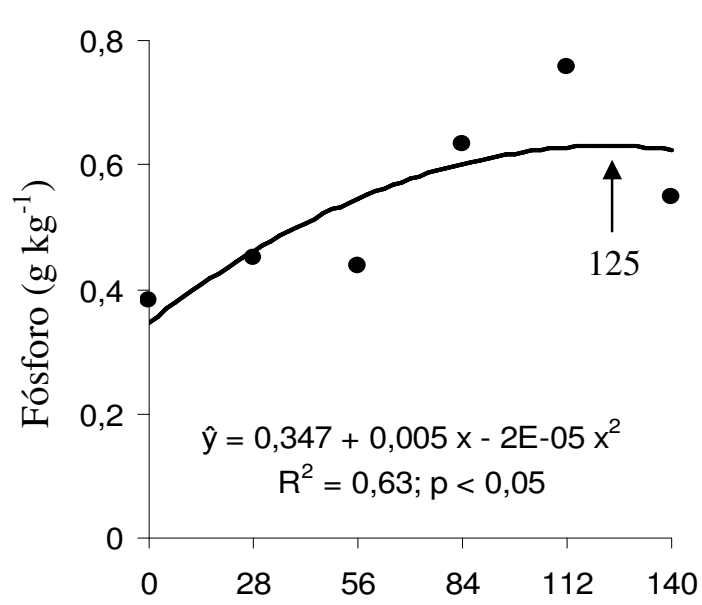

(b)

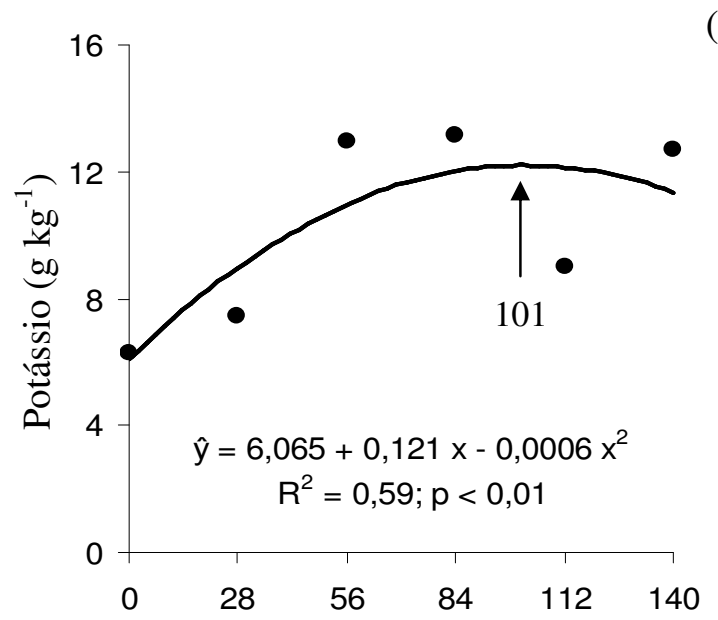

(c)
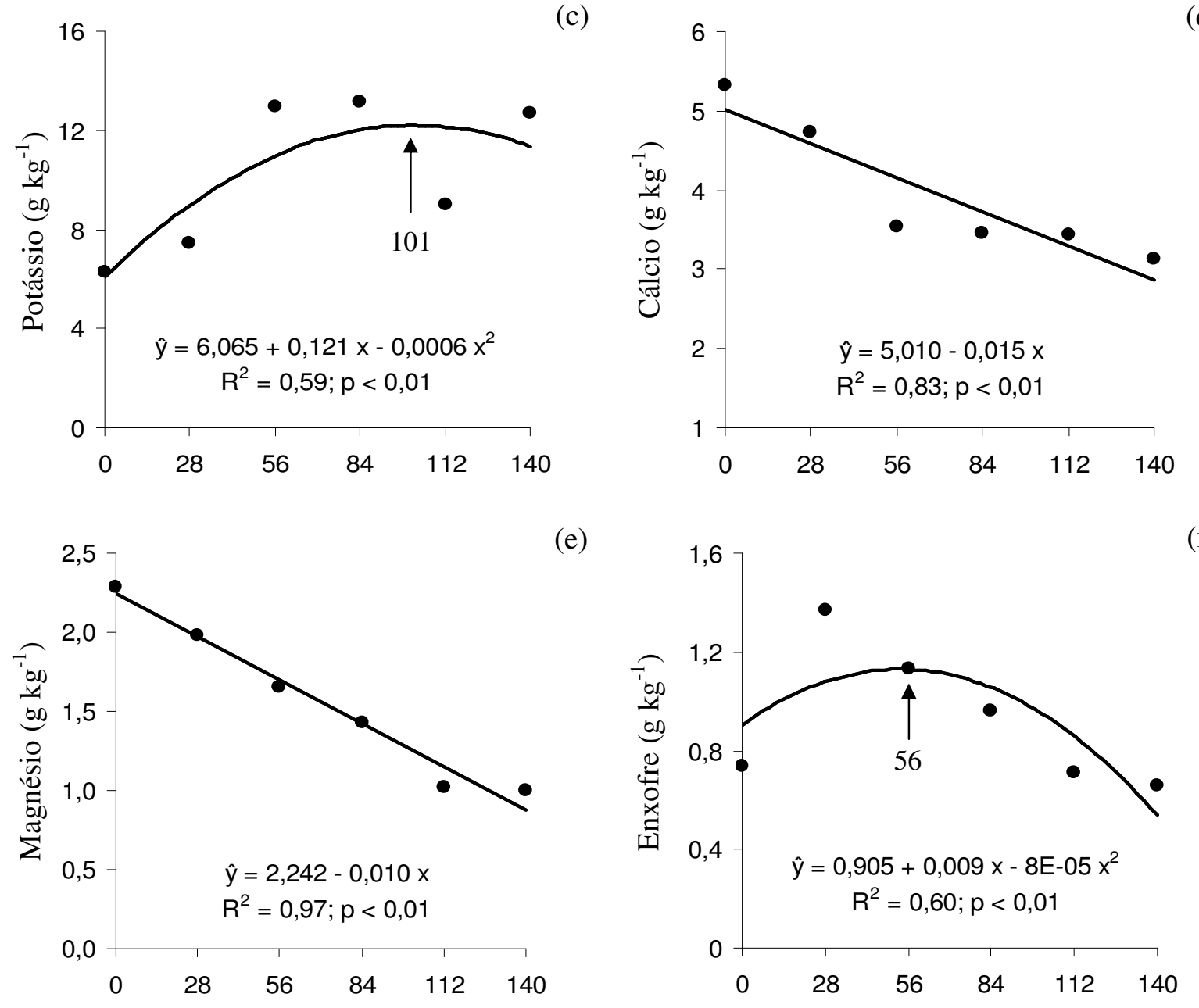

(e)

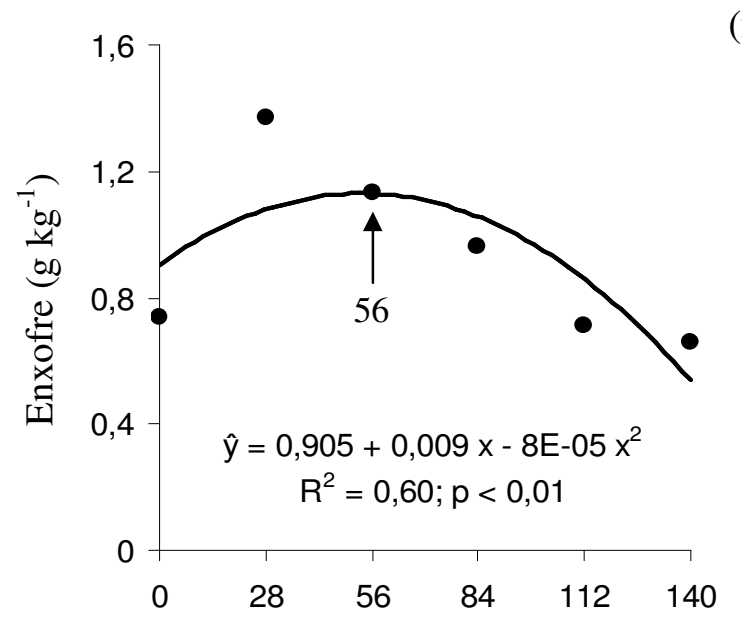

Resíduo de bauxita ( $\left.\mathrm{tha}^{-1}\right)$

FIGURA 2. Regressões entre as doses de resíduo de bauxita incorporado ao solo e o teor de macronutrientes da folha de cana-de-açúcar. Regressions between the doses of bauxite residue incorporated in the soil and the rate of macronutrients of the sugarcane leaf. 
Com a adição do resíduo de bauxita ao solo, houve acréscimo na concentração de fósforo na folha até a dose de $125 \mathrm{t} \mathrm{ha}^{-1}$; doses superiores diminuem a absorção desse nutriente pela cultura (Figura $2 \mathrm{~b}$ ). $\mathrm{O}$ aumento na absorção de fósforo pode ser explicado pelo aumento da disponibilidade desse nutriente no solo. O resíduo de bauxita, pobre em fósforo, aumentou a disponibilidade do nutriente no solo em função da elevação do $\mathrm{pH}$. Com o aumento de fósforo no solo, a cada incremento do resíduo, maior foi a absorção pela planta. Segundo RAIJ (1991), o teor de fósforo mínimo adequado na parte colhida da cana-de-açúcar é de $0,08 \mathrm{~g} \mathrm{~kg}^{-1}$, e os teores encontrados neste experimento são bem superiores, mas o excesso de fósforo, segundo o mesmo autor, não parece ser um problema sério para as plantas, já que o "consumo de luxo" é transferido para os polifosfatos e outros fosfatos, sem afetar o crescimento.

A concentração de potássio nas folhas também apresentou comportamento quadrático semelhante ao observado para o fósforo, sendo a maior concentração desse nutriente obtida quando se incorporam $101 \mathrm{t} \mathrm{ha}^{-1}$ do resíduo ao solo (Figura 2c). O aumento dos teores de potássio na planta, em função das doses, pode ser explicado pelo mesmo motivo ocorrido com fósforo. O aumento das doses levou ao aumento de potássio no solo, e esse aumento acarretou maior absorção por parte da planta. Outro motivo que está associado à queda de potássio a partir da dose de $101 \mathrm{t} \mathrm{ha}^{-1}$, é a grande quantidade de sódio que competiria com os íons de potássio, por sítios de ligações nos coloides do solo, causando sua depleção.

Os teores encontrados de potássio na planta de cana-de-açúcar estão acima dos limites mínimos exigidos para o bom desenvolvimento da planta, sendo que o limite mínimo, descrito por RAIJ (1991), para a parte colhida da cana-de-açúcar, é $1,10 \mathrm{~g} \mathrm{~kg}^{-1}$.

Os teores de cálcio e de magnésio na planta diminuíram linearmente com o da dose de resíduo de bauxita (Figura 2d e 2e). Os íons de cálcio na solução do solo podem ser perdidos na água de percolação, ser absorvidos pela planta, ser adsorvidos ao redor de partículas que constituem o complexo coloidal do solo ou tornarem-se insolúveis, como um composto secundário de cálcio. Especificamente neste estudo, a primeira hipótese pode ser descartada. Uma das causas da diminuição da absorção de cálcio pela planta está no aumento de cálcio da solução, fazendo com que o equilíbrio entre solução do solo e complexo coloidal tende a deslocar-se para o complexo coloidal, ou seja, algum cálcio passa da solução do solo para a fase sólida, sendo por ele adsorvido (COELHO \& VERLEMGIA, 1988), explicando, assim, a diminuição dos teores de cálcio em função do aumento das doses.

Com o aumento da dose, houve aumento do cálcio disponível no solo (Figura 1d), o que não explica a diminuição dos teores na planta. As doses de cálcio também são altas para prover sua insolubilização e ainda ser disponível. Com essa transformação, o cálcio não seria absorvido pela planta (NOBILE, 2005). Contudo, os teores adequados para o cálcio na planta são de 2 a $8 \mathrm{~g} \mathrm{~kg}^{-1}$, e os teores encontrados, mesmo com a diminuição, encontram-se dentro dos limites aceitáveis, de acordo com RAIJ et al. (1996). Semelhantemente ao cálcio, como era de se esperar, o aumento das doses de resíduo de bauxita diminuíram a quantidade de magnésio absorvido, em função da sua adsorção no solo, formação de compostos ou diminuição do sistema radicular.

Os níveis adequados de magnésio em plantas, segundo RAIJ (1991), variam de 2 a $5 \mathrm{~g} \mathrm{~kg}^{-1}$; as aplicações acima de $56 \mathrm{t} \mathrm{ha}^{-1}$ reduziram esses teores para muito baixo. A aplicação de $28 \mathrm{t} \mathrm{ha}^{-1}$, mesmo com a diminuição na absorção pela planta, continua dentro da faixa ideal para um bom desenvolvimento.

Para RAIJ (1997), ao contrário do que acontece com os cátions $\mathrm{Ca}^{+2}$ e $\mathrm{Mg}^{+2}$, mais retidos na camada arável do solo, $\mathrm{o} \mathrm{SO}_{4}^{-2}$ enfrenta, nessa camada, três fatores que dificultam sua permanência.

O primeiro é a presença de matéria orgânica, que reduz a absorção por óxidos e aumenta a carga negativa do solo, portanto repelindo sulfatos. O segundo é o aumento do $\mathrm{pH}$ e a liberação de sulfatos adsorvidos. Finalmente, os fosfatos aplicados em adubações ocupam, preferencialmente, as posições de troca que seriam ocupadas por sulfatos. 
A elevação do $\mathrm{pH}$, provocada pela adição do resíduo de bauxita (Figura 1a), aumentou os teores de enxofre no solo (Figura 1f) e, consequentemente, fez com que as plantas absorvessem mais enxofre até a dose de $56 \mathrm{t} \mathrm{ha}^{-1}$ de resíduo, a partir da qual o aumento das doses do resíduo proporcionou reduções nos teores de enxofre na planta.

A quantidade de massa seca produzida é um parâmetro importante para ter ideia da produção da cultura em relação aos tratamentos testados. A quantidade de massa seca reflete o tratamento que a cultura recebeu, podendo ser maior ou menor em função dos tratos culturais. As doses do resíduo de bauxita incorporadas ao solo proporcionaram efeito quadrático na produção de massa seca (Figura 3) da cana-de-açúcar, sendo a máxima produção atingida na dose de $64 \mathrm{t} \mathrm{ha}^{-1}$ do resíduo incorporado ao solo, e a utilização de doses superiores seriam prejudiciais à produção de massa seca.

PEARSON et al. (1966) e OLIVEIRA (1983), estudando o efeito de sais, também obtiveram decréscimos no peso de matéria seca, estando de acordo com os resultados encontrados.

Portanto, fica demonstrado que a aplicação do resíduo da mineração de bauxita pode ser uma opção interessante para a agricultura na medida em que fornece os nutrientes de plantas e permite destinação técnica aos mesmos, contemplando aspectos relacionados a menor impacto desse material no ambiente. Cabe aqui ressaltar a importância de estudos sobre a aplicação do resíduo de bauxita na agricultura, uma vez que este é apenas o passo inicial para o uso do produto como condicionador de solos.

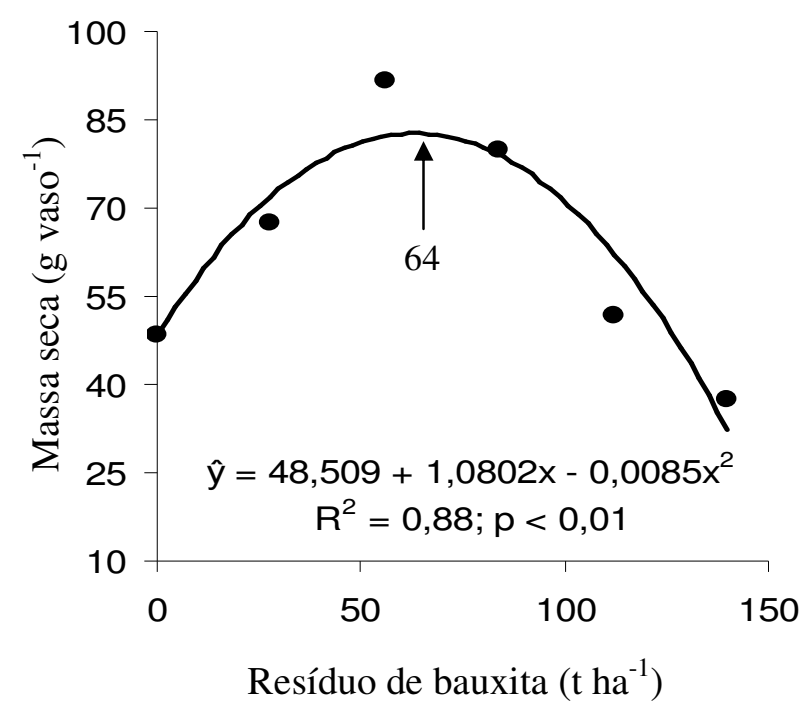

FIGURA 3. Regressão entre as doses de resíduo de bauxita incorporado ao solo e a produção de massa seca da cana-de-açúcar. Regressions between the doses of bauxite residue incorporated in the soil and the rate of macronutrients of the sugarcane leaf.

\section{CONCLUSÕES}

A incorporação do resíduo de bauxita no solo proporcionou aumento nos teores dos macronutrientes do solo; apenas para o enxofre, doses acima de $83 \mathrm{t} \mathrm{ha}^{-1}$ proporcionaram reduções do nutriente. Já para os teores de macronutrientes determinados na folha, doses acima de 70,5; 125; 101 e $56 \mathrm{t} \mathrm{ha}^{-1}$ diminuíram os teores de nitrogênio, fósforo, potássio e enxofre, respectivamente. Para o cálcio e o magnésio, a utilização do resíduo proporcionou a diminuição dos seus teores foliares. A dose do resíduo de bauxita, em que houve a maior produção de massa seca da cana-de-açúcar, foi de $64 \mathrm{t} \mathrm{ha}^{-1}$. 


\section{AGRADECIMENTOS}

À ALCOA Alumínio S.A., pelo auxílio financeiro durante o estudo. À Usina Santa Adélia, pelo fornecimento das mudas de cana-de-açúcar. Ao Departamento de Engenharia Rural, pela ajuda e pelo apoio na realização do trabalho.

\section{REFERÊNCIAS}

BERNSTEIN, L.; HAYWARD, H.E. Physiology of tolerance. Annual Review of Plant Physiology, Palo Alto, v.9, p.25-46, 1958.

COELHO, F.S.; VERLEMGIA, F. Fertilidade do Solo Campinas: Instituto Campineiro de Ensino Agrícola Agronômico. 1988. 384 p.

DOORENBOS, J.; KASSAM, A.H Efeito da água no rendimento das culturas. UFPB: Campina Grande: 1994. 306 p. (Estudos FAO: Irrigação e Drenagem, 33).

FERREIRA, C.G. Estudos sobre o comportamento de espécies florestais em áreas degradadas pela disposição de resíduo de bauxita através do uso de solo de camada superficial e gesso. $2001.117 \mathrm{f}$. Tese (Doutorado em Ciências Agroambientais) - Centro de Estudos Ambientais, Universidade Estadual Paulista, Rio Claro, 2001.

FORTIN, J.; KARAM, A. Phosphorus sorption by red mud residue as affected by concentration and reaction time. Agrochimica, Quebec, v.45, n.2, p.55-66, 2001.

HARTLEY; THORPE. Red mud stabilized limestone road base trial. Alcoa of Australian Ltd. Pinjarra Refinery. A report to Alcoa by Hartley Thorpe Consulting Chartered Engineers, West Perth, 1980.

LANARV. LABORATÓRIO NACIONAL DE REFERÊNCIA VEGETAL. Análise de corretivos, fertilizantes e inoculantes: métodos oficiais do Laboratório Nacional de Referência Vegetal. Brasília: LANARV, 1988. 104 p.

McPHARLIN, I.R.; JEFFERY, R.C.; TOUSSAINT, L.F.; COOPER, M. Phosphorus, nitrogen, and radionuclide retention and leaching from a Joel sand amended with red mud/gypsum. Communications in Soil Science and Plant Analysis, Collingwood, v.25, n.17-18, p.2.925-2.944, 1994.

MALAVOLTA, E.; VITTI, G.C.; OLIVEIRA, S.A. Avaliação do estado nutricional das plantas: princípios e aplicações. 2.ed. rev. e atual, Piracicaba: POTAFÓS, 1997. 319 p.

MONTERO, J.I.; CASTILLA, N.; GUTIERREZ DE RAVÉ, E.; BRETONES, F. Climate under plastic in the Almeria. Acta Horticultural, Addis Abeba, v.170, n.1, p.227-234, 1985.

NOBILE, F.O. de. Efeito da aplicação de resíduo da mineração de bauxita no solo e na planta de cana-de-açúcar. Jaboticabal, 2005. 117 f. Dissertação (Mestrado em Ciência do Solo) - Faculdade de Ciências Agrárias e Veterinárias, Universidade Estadual Paulista, Jaboticabal, 2005.

OLIVEIRA, F.A. Efeito da salinidade de água de irrigação sobre algumas características do solo e da cultura de arroz (Oryza sativa, L.). 1983. 139 f. Dissertação (Mestrado em Nutrição de Plantas) - Escola Superior de Agricultura “Luiz de Queiroz”, Universidade de São Paulo,Piracicaba, 1983.

PEARSON, G.A.; AYERS, A.D.; EBERHARD, D.L. Relative salt tolerance of rice during germination and early seedling development. Soil Science, Baltimore, v.103, n.3, p.151-156, 1966.

RAIJ, B. van. Fertilidade do solo e adubação. São Paulo: Ed. Agronômica Ceres, 1991. 343 p.

RAIJ, B. van; ANDRADE, J. C. de; CANTARELLA, H.; QUAGGIO, J.A. Análise química para Avaliação da Fertilidade de Solos Tropicais. Campinas: Instituto Agronômico de Campinas, 2001. $285 \mathrm{p}$. 
RAIJ, B. van; CANTARELLA, H.; QUAGGIO, J.A.; FURLANI, A.M.C. Recomendação de adubação e calagem para o Estado de São Paulo. Campinas: [s.n.], 1997. 285 p.

ROBERTSON, W.J.; JEFFERY, R.C.; MCPHARLIN, I.R. Residues from bauxite-mining (red mud) increase phosphorus retention of a Joel sand without reducing yield of carrots. Communications in Soil Science and Plant Analysis, Western Australia, v.28, n.13-14, p.1.0591.079, 1997.

SAS INSTITUTE, SAS User's guide. Cary, 1999. 595 p.

SOUZA, H.R. de. Aproveitamento de lama vermelha para produção de agregado para a construção civil. In: do Ó, O.M.P. (Coord). Recuperação de rejeitos da indústria metalúrgica. Volta Redonda: Associação Brasileira de Metais, 1989. p.81-92.

SUMMERS, R.N.; SMIRK, D.D.; KARAFILIS, D. Phosphorus retention and leachiest from sandy soil amended with bauxite residue (red mud). Australian Journal of Soil Research, Collingwood, v.34, n.4, p.555-567, 1996.

WARD, S.C. The use of the fine residue from bauxite refining as a soil amendment. 1986. $318 \mathrm{f}$. Tese (PhD em Agronomia) - School of Environmental and Life Science, Murdoch University, Perth, 1986.

WONG, J.W.C. Sodium release characteristics in revegetation of fine residue bauxite refining residue (red mud). 1990. 443 f. Tese (PhD em Agronomia) - School of Environmental and Life Science, Murdoch University, Perth, 1990. 